\title{
Knowledge, health seeking behavior and barriers for treatment of reproductive tract infections among married women of reproductive age in Delhi
}

\author{
Preety Doley $^{1}$, Geeta Yadav ${ }^{1 *}$, Monika Gupta², Sumathi Muralidhar ${ }^{3}$
}

\begin{abstract}
${ }^{1}$ Department of Community Medicine, ${ }^{2}$ Department of Obstetrics and Gynaecology Vardhaman Mahavir Medical College and Safdarjung Hospital, New Delhi, India

${ }^{3}$ Department of Microbiology, Apex Regional STD Laboratory and State Reference Laboratory for HIV Vardhaman Mahavir Medical College and Safdarjung Hospital, New Delhi, India
\end{abstract}

Received: 27 November 2020

Accepted: 04 January 2021

\section{*Correspondence:}

Dr. Geeta Yadav,

E-mail: yadavgeeta07@gmail.com

Copyright: (c) the author(s), publisher and licensee Medip Academy. This is an open-access article distributed under the terms of the Creative Commons Attribution Non-Commercial License, which permits unrestricted non-commercial use, distribution, and reproduction in any medium, provided the original work is properly cited.

\section{ABSTRACT}

Background: Reproductive tract infections including sexually transmitted infections are an important public health problem among women of reproductive age group in developing countries. The perceptions or taboos related to RTIs act as an obstacle for seeking treatment ultimately leading to complications. The aim of the study was to assess the knowledge, health seeking behavior and barriers for treatment of reproductive tract infections among married women of reproductive age in Delhi.

Methods: A community based cross-sectional study was undertaken in an urban field practice area of department of Community Medicine of VMMC and Safdarjung Hospital, New Delhi from November 2017 to April 2019. Sample size of 270 was collected using predesigned and pre- tested questionnaire by systematic random sampling.

Results: Mere $16.6 \%$ of the women knew about symptoms of RTI/STIs. Out of 81 women having RTI/STI in past 3 months $30 \%$ did not seek treatment and out of $70 \%$ who took treatment for RTI, $30 \%$ did not complete treatment. Majority of the women who sought treatment preferred government hospital. The main barrier for seeking treatment was embarrassment, not considering it as an important health problem, lack of time.

Conclusions: The overall knowledge about symptoms, mode of spread of RTIs/STIs was very poor among the study participants. Women seeking treatment are not completing it. Thus, there is need to emphasize on spreading knowledge about symptoms, mode of spread, need for treatment and its completion and clearing barriers related to RTI/STI among women.

Keywords: Reproductive tract infections, knowledge, Barriers, Treatment seeking behavior

\section{INTRODUCTION}

Reproductive tract infections (RTIs) and sexually transmitted infections (STIs) are a major health concern among women of reproductive age group. According to WHO, it is estimated that more than one million STIs are acquired every day and annually about 376 million new infections with one of four curable STIs i.e Chlamydia, gonorrhea, syphilis and trichomoniasis, are reported worldwide. ${ }^{1}$ Women particularly those living in low and middle income countries are highly vulnerable to RTIs/STIs due to poverty and gender inequity which act as an important barrier to access health care services. ${ }^{2}$ In India, the prevalence of self-reported RTI symptoms among women varies from $11-72 \%$ and most of the women with symptoms of RTI either never seek treatment, or delay seeking treatment. ${ }^{3}$ Despite the availability of low cost and appropriate technologies for 
management of RTIs/STIs, very few seek treatment either due to lack of knowledge about it or due to the existing taboos regarding sexual and reproductive health. ${ }^{4}$ This is an important aspect to be taken care of, as majority of RTIs/STIs have no symptoms, or mild symptoms, which if left untreated can lead to serious complications, like pelvic inflammatory disease, ectopic pregnancy, infertility, cervical cancer and can enhance the transmission of Human Immunodeficiency Virus (HIV). ${ }^{5}$ Along with the health consequences, women also go through lot of emotional distress due to gynecological morbidity which leads to social consequences. ${ }^{6}$

Limited decision making by women, inability to recognize symptoms as an important problem, embarrassment and health care facility related factors, such as lack of privacy, absence of female doctor etc have been reported as reasons for not availing treatment from healthcare facilities. $^{3}$ It is well documented that knowledge about a health problem is an important precursor for recognizing it and taking steps to prevent it or treat it. Although we have programme for prevention and control of RTI/STI in our country but we are still far away from reaching our target, thus keeping this in mind the present community based study was carried out to assess the knowledge, health seeking behavior and barriers for treatment, among married women of reproductive age group (15- 49 years) in an urbanized village of Delhi.

\section{METHODS}

A community based cross-sectional study was undertaken in an urbanized village of Delhi, Aliganj, which is an urban field practice area of department of Community Medicine of VMMC and Safdarjung Hospital (VMMC and SJH), New Delhi from November 2017 to April 2019. Married women in the reproductive age group of 15 to 49 years, residing in the study area for more than 6 months were studied. Women suffering from any severe/debilitating illness and those who were pregnant at the time of the study were excluded.

Sample size of 270 was calculated using prevalence of RTI symptoms as $42 \%$ based on a previous study, confidence interval of $95 \%$, and relative precision as $15 \%$, non-response error as $10 \%$, and using the formula $4 \mathrm{pq} / \mathrm{d}^{2}{ }^{7}$ Sampling unit was a household which was selected using systematic random sampling. Every 6th household was visited and the eligible women were selected till the minimum desired sample size was completed. Next sixth household was selected if there were no eligible women, house was locked or unavailability at the time of visit.

An attempt was made to visit the locked house at least three times. In the selected house with more than one eligible woman, only one eligible woman was chosen by lottery method. Data was collected using a predesigned, pretested, semi-structured, semi-open ended, interviewer administered questionnaire to assess the sociodemographic factors, their knowledge of symptoms, mode of spread, delayed consequences of untreated RTIs/STIs, if RTIs/STIs are preventable or treatable etc. Participants were also questioned about their health seeking behaviors and barriers thereof, such as, whether they had suffered from RTI/STI in the past, whether treatment was taken and if not, reasons for not taking treatment.

The collected data was analyzed using licensed statistical Package for the Social Sciences (SPSS) software version 21.0 for frequencies and qualitative data was summarized as proportions, analyzed using Chi-Square/ Fisher exact test and quantitative data as mean with standard deviations. The $\mathrm{p}$ value of less than 0.05 was taken as statistically significant.

Ethical clearance for the study was obtained from Institutional Ethics Committee of VMMC and SJH and informed written consent was taken from each study participant. Strict confidentiality was maintained.

\section{RESULTS}

A total of 270 women were studied and the mean age of the study participants was $30.33 \pm 5.52$ years. Majority of them were Hindus and belonged to nuclear families, $44 \%$ were illiterate and $88.9 \%$ women were homemakers while only $4.8 \%$ were unskilled workers and majority $(80.7 \%)$ belonged to lower middle or upper-lower class as per Revised Kuppuswamy Scale 2017 (Table 1).

\section{Prevalence of RTI/STI symptoms in the past 3 months}

Out of 270 women, $81(30 \%)$ reported that they had symptoms of RTI/STI in the past three months. The most commonly reported symptom was vaginal discharge 74 $(91.3 \%)$, followed by lower abdomen pain $37(45.6 \%)$ and low backache $34(41.9 \%)$. None of the women reported genital ulcer, swelling or lump or ulcer in the groin area.

\section{Knowledge about RTI/STI}

When assessed about the knowledge of RTI/STI, mere $16.6 \%$ of women were aware about the symptoms while only $38 \%$ knew how it spreads. Very few (15.1\%) women were aware that it can be treated; only $9.6 \%$ knew that it is preventable and only $12.2 \%$ knew about consequences if it left untreated (Table 2).

Of the $16.6 \%$ women knowing about symptoms of RTI/STI, almost $3 / 4^{\text {th }}$ knew about vaginal discharge while $62.2 \%$ about pain in lower abdomen and $42.2 \%$ knew about lower backache, respectively. Relatively lesser number of women knew about other symptoms, such as burning sensation while passing urine, itching in the genital area and genital ulcer (Figure 1). 
Table 1: General characteristics of the study participants $(\mathrm{N}=270)$.

\begin{tabular}{|ll|}
\hline Age group* (in years) & Number (\%) \\
\hline$\leq 20$ & $3(1.1)$ \\
\hline $21-30$ & $171(63.6)$ \\
\hline $31-40$ & $88(32.6)$ \\
\hline $41-49$ & $8(3.0)$ \\
\hline *Mean age =30.33 years; S.D $= \pm \mathbf{5 . 5 2}$ \\
\hline Religion & $253(93.7)$ \\
\hline Hindu & $12(4.4)$ \\
\hline Muslim & $5(1.8)$ \\
\hline Others (Christian and Sikh) & \\
\hline Type of family & $221(81.9)$ \\
\hline Nuclear & $49(18.1)$ \\
\hline Joint & $118(43.7)$ \\
\hline Educational qualification & $57(21.1)$ \\
\hline Illiterate & $48(17.8)$ \\
\hline Primary school & $25(9.3)$ \\
\hline Middle school & $22(8.1)$ \\
\hline High school & \\
\hline Higher secondary school and above & $13(4.8)$ \\
\hline Occupation & $7(2.6)$ \\
\hline Unskilled worker & $9(3.3)$ \\
\hline Semi-skilled worker & $1(0.4)$ \\
\hline Skilled worker & $240(88.9)$ \\
\hline Semi professional & \\
\hline Home maker & $45(16.7)$ \\
\hline Socio economic class* & $108(40)$ \\
\hline Upper-Middle (II) & $110(40.7)$ \\
\hline Lower-Middle (III) & $7(2.6)$ \\
\hline Upper-Lower (IV) & \\
\hline Lower (V) & \\
\hline *according to Revised Kuppuswamy & Scale 2017 \\
\hline
\end{tabular}

Table 2: Distribution of study participants according to knowledge about RTI/STI (N=270).

\begin{tabular}{|ll|}
\hline Knowledge about RTI/STI & Number (\%) \\
\hline Symptoms & $45(16.6)$ \\
\hline correct mode of spread & $24(38.09)$ \\
\hline Consequences of untreated RTI/STI & $33(12.2)$ \\
\hline RTI/STI are treatable & $41(15.1)$ \\
\hline RTI/STI are preventable & $26(9.6)$ \\
\hline
\end{tabular}

Out of $38.09 \%$ women knowing how it spreads all knew about sexual transmission, while $41.2 \%$ thought that it can spread through dirty toilets and almost $21 \%$ thought it spreads through sharing same clothes.

About $61 \%$ felt that it can lead to poor maternal health while more than half knew about inability to conceive and $12 \%$ about increased susceptibility to HIV/AIDS as a consequence if it is left untreated.

\section{Health care seeking behavior and barriers related to treatment}

The health seeking behavior and barriers related to treatment of RTI/STI were assessed from those 81 study participants who had history of RTI/STI in the last three months. Out of 81 women having symptoms almost $30 \%$ did not seek treatment and out of $70 \%$ who did seek almost $30 \%$ did not take complete treatment. As can be seen $54.3 \%$ sought treatment from government doctors, $21.05 \%$ from private and almost one fourth from chemists or quacks (Table 3). Almost 59\% women left treatment when their symptoms subsided even though doses were left, while $17.6 \%$ left as they could not afford to buy the medicines. Some of the reasons for not completing treatment were not getting medicines or fear of side effect. The main barrier for not seeking treatment that they were embarrassed to go to a doctor (45.8\%) and did not consider it an important health problem $(20.8 \%)$. It was nothing abnormal (16.6\%) and even $8.3 \%$ women reported that they were too busy and had no time for seeking treatment (Figure 2).

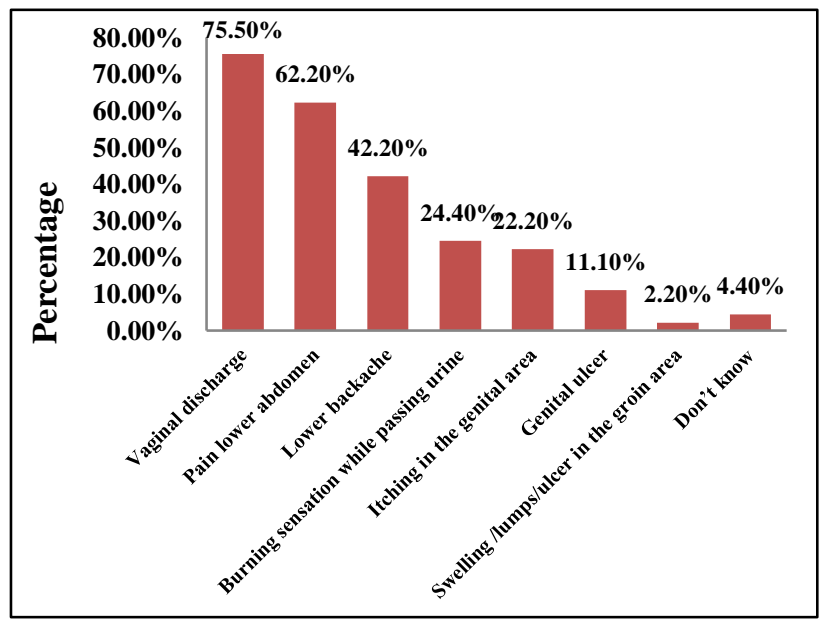

Figure 1: Knowledge about symptoms of RTI/STIs among study participants $(n=45)$.

Table 3: Health care' seeking behaviour among participants having symptoms of RTI/STI.

\begin{tabular}{|ll|}
\hline Variable & Number $(\%)$ \\
\hline Taken treatment $(\mathbf{n = 8 1 )}$ & $57(70.3)$ \\
\hline Did not take treatment $(\mathbf{n = 8 1})$ & $24(29.7)$ \\
\hline Source of treatment $(\mathbf{n = 5 7 )}$ & \\
\hline Government doctors & $31(54.3)$ \\
\hline Private doctors & $12(21.1)$ \\
\hline Others $($ Chemists, Quack etc) & $14(24.6)$ \\
\hline Complete treatment taken(n=57) & \\
\hline Yes & $40(70.1)$ \\
\hline No & $17(29.8)$ \\
\hline
\end{tabular}




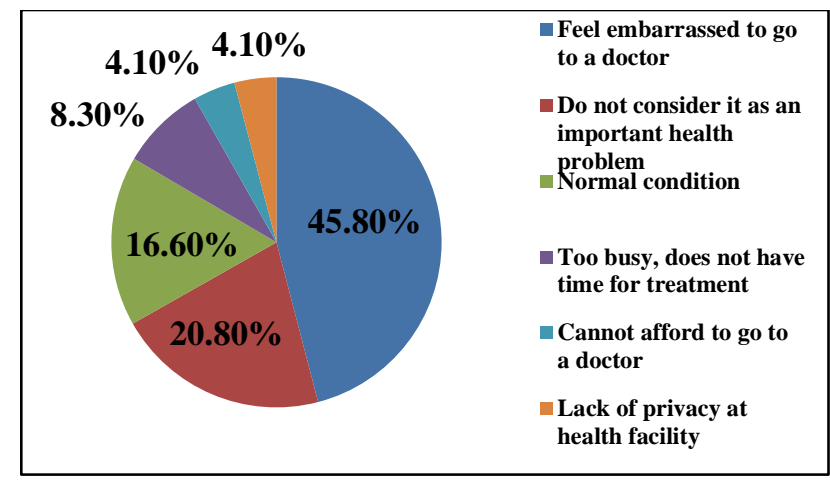

Figure 2: Distribution of the study participants according to barriers for not seeking treatment $(n=24)$.

\section{DISCUSSION}

For more than two decades we have a programme focusing on raising awareness, providing treatment for RTIs/STIs under RCH1, RCH 2 and subsequently under $\mathrm{RMNCH}$ and A but it still remain neglected. The overall knowledge was very poor among the study participants with only $16.6 \%$ knowing about symptoms of RTI/STIs which is consistent with previous studies. ${ }^{7-10}$ Most women knew about vaginal discharge $(75 \%)$ and lower abdomen pain $(62.2 \%)$ as symptoms of RTI/STIs, followed by lower backache $(42.2 \%)$. In a study conducted in Nigeria, vaginal discharge was the most commonly perceived symptom of RTIs. ${ }^{9}$ The findings in the present study was in contradiction to a study in Vietnam, where $42.2 \%$ of the women had knowledge about symptoms of RTI, $39.8 \%$ knew about genital itching and $32.9 \%$ knew about vaginal discharge. ${ }^{2}$

Having knowledge that a disease is treatable can be an important factor in deciding to take complete treatment but only $15.1 \%$ women in our study were aware that RTI/STIs are treatable and only 38\% knew about the correct mode of spread i.e. through sexual intercourse. In another study in India, 57\% women knew sexual contact as a way of transmitting RTIs whereas in contrast only $27.3 \%$ of the participants mentioned sexual contact as mode of transmission in a study conducted in Lahore. ${ }^{11,12}$ This difference in findings could be as a result of different study settings or different socioeconomic characteristics of the study participants. Incorrect knowledge about mode of spread can act as hindrance in adopting preventive measure and in present study $41.2 \%$ of the women thought it spreads through toilet seats which are similar to reported by Rabiu et al. ${ }^{9}$

$60.6 \%$ of the women reported poor maternal health as consequences of untreated RTI/STIs, followed by inability to conceive $(54.5 \%)$, increased susceptibility to HIV/AIDs and $3.03 \%$ developing cancer, while Rabiu et al reported $57.5 \%$ women knowing infertility as the complication of RTIs, followed by cervical cancer $(18.3 \%)$ and heavy menses (17.2\%). Although the proportion of women knowing about different complications differs but still in both the studies knowledge about complications is far from desirable. ${ }^{9}$

Out of 81 women having symptoms of RTI/STI in the past three months, $70.3 \%$ took treatment and $70 \%$ of those who took treatment completed the treatment. Earlier studies conducted in Delhi have also reported similar findings but in a study conducted in Bangalore only $29.1 \%$ of the symptomatic women took treatment, which is lower than in our study but the proportion of women completing treatment were comparable..$^{7,13,14} \mathrm{We}$ found that government hospitals were favored for seeking treatment by almost half of the women as compared to private doctors and others which is consistent with that reported by Sridevi et al while few other studies have reported women preferring private health facility. ${ }^{15}$ Accessibility, availability and timings of Government health facilities in the study area could be some of the possible reasons for this difference..$^{9,10,16}$

Studies have shown that poor access to healthcare, poor knowledge or awareness act as barriers for treatment, which contribute to increase in prevalence of RTI/STIs. ${ }^{15,17,18}$ The major barriers for not taking treatment in our study were embarrassment (45.8\%) followed by not an important health problem (20.8\%). Considering it as before not normal condition, being too busy, not being able to afford to go to a doctor and lack of privacy in the health facility were some of the other reasons why women were not seeking treatment. Similar findings have been reported with regard to treatment seeking behavior and barrier for seeking treatment for RTI/STI by various other studies in India. ${ }^{14,16}$ Mathew et al reported that factors such as, considering gynecological morbidity as normal, shyness, not knowing how to explain the symptoms, lack of money, high cost of service, distance of the health care facility, fear of complication etc were the barriers reported for seeking treatment, few of the barriers were different from that in our study. ${ }^{19}$ This difference could be attributed to difference in study settings, urbanized village compared to rural settings, and different level of education among the respondents.

\section{Limitations}

Use of quantitative research methodology is the main limitation of the study as qualitative research methods with key informant interviews and focus group discussions would have been more robust methods for exploring some of the barriers for seeking care for RTI/STI and exploring why after putting so much effort in improving knowledge and providing treatment for it women are still hesitating to come forward for it.

\section{CONCLUSION}

Overall, this study showed poor knowledge among study participants about the symptoms of RTI/STI. Moreover, 
less than one-fourth of the women knew that RTI/STIs are either treatable or preventable. Not many women were aware of the correct mode of spread of RTI/STI, while some women had the wrong perception that RTI/STI spread through dirty clothes or by sharing clothes, which indicates the need for information, education and communication regarding the signs and symptoms of RTI/STI, to create awareness among the target population. Although higher proportion of women who had past history of RTI/STI took treatment, nearly one-fifth of the patients did not complete treatment. This emphasizes the need for involvement of health workers for RTI/STI case management, and counselling at community level, repeated health education sessions regarding benefits of treatment and organizing weekly clinics to reduce the burden of the disease and to make services more patient friendly and accessible so that women do not hesitate in taking treatment.

\section{ACKNOWLEDGMENTS}

Authors would like to thank all those who involved in the study.

\section{Funding: No funding sources}

Conflict of interest: None declared

Ethical approval: The study was approved by the Institutional Ethics Committee

\section{REFERENCES}

1. World Health Organization. Factsheet sexually transmitted infections (STIs) Updated June 2019. Available at http:// www. who. int/ newsroom/newsletter. Accessed on 10 April 2020.

2. Nielsen A, Lan PT, Marrone G, Phuc HD, Chuc NTK, Lundborg CS. Reproductive tract infections in rural vietnam women's knowledge and healthseeking behavior: a cross-sectional study. Health Care Women Int. 2016;37:392-411.

3. Nagarkar A, Mhaskar P. A systematic review on the prevalence and utilization of health care services for reproductive tract infections/sexually transmitted infections: Evidence from India. Indian J Sex Transm Dis AIDS. 2015;36(1):18-25.

4. Shingade PP, Kazi Y, Lh M. Treatment seeking behavior for sexually transmitted infections/reproductive tract infections among married women in urban slums of Mumbai, India. South East Asia J Public Health. 2015;5:65-70.

5. Wijgert JH, Morrison CS, Brown J, Kwok C, Pol B, Chipato $\mathrm{T}$, et al. Disentangling contributions of reproductive tract infections to HIV acquisition in African Women. Sex Transm Dis. 2009;36:357-64.

6. Puthuchira RR, Athimulam KR. Care seeking behaviour and barriers to accessing services for sexual health problems among women in rural areas of Tamilnadu State in India. J Sex Transm Dis. 2014;2014:292157.
7. Verma A, Kumar J, Meena, Banerjee B. A comparative study of prevalence of RTI/STI symptoms and treatment seeking behaviour among the married women in rural and uban areas of Delhi. Int J Reprod Med. 2015;563031:1-8.

8. Pandey B, Shukla DK. Socio-economic determinants of reproductive tract infections affecting the women (15-49 years): a cross sectional study in a tertiary care hospital of Chhattisgarh. Int J Community Med Public Health. 2018;5(7):3130-5.

9. Rabiu KA, Adewunmi AA, Makinlusi A, Akinola O I. Female reproductive tract infections: understanding and care seeking behavior among women of reproductive age in Lagos, Nigeria. BMC Women's Health. 2010;10:8.

10. Hegde SK, Agrawal T, Ramesh N, Sugara M, Joseph PM, Singh S, Thimmaiah S. Reproductive tract infections among women in a peri-urban under privileged area in Bangalore, India: Knowledge, prevalence, and treatment seeking behavior. Ann Trop Med Public Health. 2013;6:215-20.

11. Nigam VS, Srivastava VK. Knowledge about sexually transmitted disease (STD) among the women in a rural population of Uttar Pradesh. IJMSCI. 2018;5:3966-9.

12. Chaudhry R, Majrooh A, javed s. understanding and care seeking behavior of reproductive tract infections and sexually transmitted diseases among married women attending a tertiary care hospital, Lahore, Pakistan. Biomedica. 2013;29:175-80.

13. Bhilwar M, Pannalal, Sharma N, Bhalla P, Kumar A. Prevalence of reproductive tract infections and their determinants in married women residing in an urban slum of North-East Delhi, India. J Nat Sci Bio Med. 2015;6:S29-S34.

14. Ratnaprabha GK, Thimmaiah S, Johnson AR, Ramesh N. Prevalence and awareness of reproductive tract infections among women in selected underpriviledged areas of Banglore City. Int J Med Sci Public Health. 2015;4:1691-6.

15. Devi BS, Swarnalatha N. Prevalence of RTI/STI among reproductive age women (15-49 years) in urban slums of Tirupati town, Andhra Pradesh. Health Popul Perspect Issues. 2007;30:56-70.

16. Khargekar VC, Koujalgi S. A study on the prevalence of sexually transmitted infections, the health care seeking behavior and the barriers for the treatment of sexually transmitted infections in the urban slums of Davangere. Int J Med Sci Public Health. 2015;4:823-8.

17. Li C, Han HR, Lee JE, Lee M, Kim MT. Knowledge, behaviour and prevalence of reproductive tract infections: a descriptive study on rural women in Hunchun, China. Asian Nurs Res (Korean Soc Nurs Sci). 2010;4:122-2.

18. Chellan R. Socio-demographic determinants of reproductive tract infection and treatment seeking behaviour in rural Indian women. New Delhi: Centre for the Study of Regional Development, School of Social Sciences, Jawaharlal Nehru University. 
Available at http:// paa 2007. princeton. edu/ download. aspx?submissionId=70668. Accessed on 14 February 2020.

19. Mathew L, Ansuya, Francis LA. Percieved barriers for utilization of health care system among married women with gynaecological morbidity in Udupi
Taluk, Karnataka. Indian J Public Health Development. 2016;9:85-8.

Cite this article as: Doley P, Yadav G, Gupta M, Muralidhar S. Knowledge, health seeking behavior and barriers for treatment of reproductive tract infections among married women of reproductive age in Delhi. Int J Reprod Contracept Obstet Gynecol 2021;10:591-6. 